BBA 75633

\title{
INTERFACIAL BARRIERS TO THE TRANSPORT OF STEROLS AND OTHER ORGANIC COMPOUNDS AT THE AQUEOUS POLYSORBATE
} 8O-HEXADECANE INTERFACE

\author{
ANWAR B. BIKHAZI AND WILLIAM I. HIGUCHI \\ College of Pharmacy, University of Michigan, Ann Arbor, Mich. 48104 (U.S.A.) \\ (Received December 29th, 1970)
}

SUMMARY

I. The interfacial barrier controlled transport of some biologically important solutes in the aqueous polysorbate 80 -hexadecane system were investigated by means of the multiparticulate dispersion technique.

2. It was shown that the resistances to transport of cholesterol, $\beta$-sitosterol, desmosterol, 20 $\alpha$-hydroxycholesterol, and vitamin $\mathrm{D}_{\mathbf{3}}$ across the oil/water interface, were of the order of $\mathrm{IO}^{3}-\mathrm{IO}^{7}$ times greater than those for diffusion controlled mechanisms.

3. The effects of changing the polysorbate- 80 concentration upon the transport rates of the solutes were investigated. Cholesterol, $\beta$-sitosterol, and desmosterol showed little or no change of their permeability coefficients in the $0 . \mathrm{I}-\mathrm{I} \%$ range of the surfactant concentration. These results suggest that for these compounds the drug-micelle complex is involved in the "transition" state. The data further suggest that a two-step mechanism is involved, viz. the approach of the solute loaded micelle to the interface and the unloading of the solute at the interface.

4. One of the interesting findings of this research relevant to biology is the possible correlation of these experiments to the intestinal absorption of cholesterol and $\beta$-sitosterol. The present studies show that the interfacial resistance for $\beta$-sitosterol is about ro times greater than that for cholesterol, while rat intestinal absorption studies how that cholesterol is absorbed $5^{-I 0}$ times more rapidly than $\beta$-sitosterol.

\section{INTRODUCTION}

In the past few years, multicomponent and multicompartment diffusional models have been successfully employed, theoretically and experimentally to provide meaningful insights to the transport of solutes across biologically important membranes $^{1-13}$. While the understanding of the influence of numerous factors has been partially achieved, e.g., the oil/water partition tendencies of the solute and the $\mathrm{pH}$ and buffer characteristics of the medium, relatively little is known about interfacial barriers to interphase transport. It would appear that a mechanistic understanding of interfacial resistances to solute transport should be valuable to the understanding of absorption, distribution, and metabolism of drugs and other biologically important compounds, 
Recent investigations in our laboratories ${ }^{5-8,10-13}$ have provided techniques that are well suited to the quantitative characterization of interfacial barriers to interphase transport of solutes. The techniques have promised to be significantly more sensitive and accurate ${ }^{11}$ than previous methods ${ }^{4,14}$.

The purpose of this paper is to present the development of the above mentioned techniques and their application to the study of the interfacial barriers to oil/water interphase transport of a number of biologically important organic solutes. One set of compounds studied here were the biochemically related sterols, cholesterol, $\beta$-sitosterol, desmosterol, and $20 \alpha$-hydroxycholesterol. These compounds have a common basic sterol nucleus with slight chemical differences in their side chains. In addition to these, other compounds of biopharmaceutic interest were included in this study.

KEY TO SYMBOLS USED IN THE TEXT

$G_{j}$, flux of solute transport; $a_{j}$, oil droplet radius; $D$, diffusion coefficient; $c_{b}$, total solute concentration in the bulk phase; $c_{s}$, solute concentration at the surface of the interfacial barrier region; $P$, permeability coefficient; $K$, partition coefficient; $c_{o j}$, solute concentration in oil droplets of radius $a_{j} ; c^{\prime}{ }_{b j}, c^{\prime}{ }_{b j}=c_{o j} / K ; V_{o j}$, volume of oil droplet of radius $a_{j} ; t$, time; $\Delta N_{j}$, number of droplets of sizes between $a_{j}$ and $a_{j+I} ; L$, largest oil droplets in the system; $Q_{u}$, amount of solute remaining in uptake experiments $=c_{b} ; Q_{r}$, amount of solute release $=c_{b}-c^{\prime}{ }_{b} ; c^{\prime}{ }_{b}$, initial solute $(t=0)$ concentration in release experiments; $c_{o i}$, initial solute $(t=0)$ concentration in the oil phase for a release experiment.

\section{METHODOLOGY AND THEORETICAL CONSIDERATIONS}

The method selected involved the use of oil droplets dispersed in aqueous media into which or from which the transport of solute is followed with time ${ }^{10,11}$. The following discussion considers the relevant interrelationships between experiment and the theory which incorporates the various parameters physically determining the system.

The model shown in Fig. I described an oil droplet of radius $a_{j}$ suspended in an aqueous surfactant phase. The region of the interfacial barrier as shown in the model is hypothetically drawn to indicate the possibility of resistances to solute transport across the oil/water interphases. This barrier is best described by a transport coefficient which can be a function of solute, surfactant, and oil characteristics.

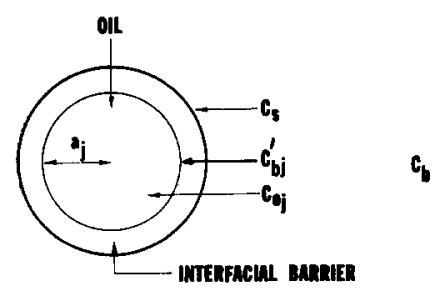

Fig. I. The physical model that describes the uptake and/or release of solutes across the oil droplet. $a_{j}$, droplet radius; $c_{o j}$, solute concentration in the oil phase; $c_{s}$, aqueous solute concentration just outside the adsorbed film; $c_{b}$, solute concentration in the aqueous polysorbate 80 phase; $c_{b j}^{\prime}$, solute concentration at the oil/water interface. 
Referring to the model (Fig. I) for an oil droplet of radius, $a_{j}$, the rate of solute transport from the bulk phase to the surface of the barrier is given by Eqn. I (ref. I5)

$$
G_{j}=4 \pi a_{j} D\left(C_{b}-C_{s}\right)
$$

where $D$ is the effective diffusion coefficient for the solute in the polysorbate 80 solution, $c_{b}$ is the total solute concentration in the bulk phase, and $c_{s}$ is the solute concentration at the surface of the barrier region shown in the model.

For the same solute species crossing the interfacial barrier region, the transport rate is given by Eqn. 2 (ref. I6)

$$
G_{j}=4 \pi a_{j}^{2} P\left(c_{s}-c^{\prime}{ }_{b j}\right)
$$

where $P$ is the apparent permeability coefficient (which may also be defined as the apparent first-order interface rate constant for the solute transport) for the interfacial barrier, and $c_{b j}^{\prime}$ (solute concentration at the oil/water interface) is defined by

$$
K=c_{o j} / c^{\prime}{ }_{b j}
$$

where $K$ is the effective hexadecane-polysorbate 80 partition coefficient for the solute and $c_{o j}$ is the solute concentration in the oil droplet.

Eqns. I and 2 apply to both uptake and release of the solute by the oil droplet, the two situations differing only by the difference in sign of the concentration gradient. When $G_{j}$ is positive, the situation is for uptake; when $G_{j}$ is negative, one has solute release from the droplet.

Solving Eqns. I and 2 for $c_{s}$ and combining them, the rate of solute transport into (or out of) the droplet is then given by

$$
G_{j}=\frac{4 \pi a_{j}^{2} P D\left(c_{b}-c^{\prime}{ }_{b j}\right)}{D+a_{j} P}
$$

If $a_{j} P \ll D$, then $a_{j} P$ may be neglected in the denominator of Eqn. 4 which then reduces to

$$
G_{j}=4 \pi a_{j}^{2} P\left(c_{b}-c^{\prime}{ }_{b j}\right)
$$

which is the limiting expression for the interfacial barrier controlled transfer of the solute.

The rate of change of the solute concentration in the oil with respect to time may also be written as

$$
G_{j}=V_{o j} \frac{\mathrm{d} c_{o j}}{\mathrm{~d} t}
$$

where $V_{o j}=4 /{ }_{3} \pi a_{j}^{3}$ is the volume of the oil droplet, and $t$ is the time.

Eqns. 3, 4 and 6 may be combined to give

$$
\frac{\mathrm{d} c_{o f}}{\mathrm{~d} t}=\frac{3^{D P}\left(c_{b}-\frac{c_{o f}}{K}\right)}{a_{j}\left(D+a_{j} P\right)}
$$

From material balance considerations in the system, one can write

$$
\frac{\mathrm{d} c_{b}}{\mathrm{~d} t}=-\frac{4 \pi}{3 V} \frac{\pi}{V_{W}} a_{j}^{3} \Delta N_{j} \frac{\mathrm{d} c_{o j}}{\mathrm{~d} t}
$$


where $V_{W}$ is the volume of the aqueous phase, $\Delta N_{j}$ is the number of droplets of sizes between $a_{j}$ and $a_{j+1}$, and $L$ represents the largest oil droplets in the system.

Eqns. 7 and 8 may be used to solve for $c_{b}$ as a function of time when $V_{W}, D, P$, $K$, and the particle size distribution are known (Table I, ref. Io). However, this cannot be done analytically, and one must resort to numerical methods of analysis (see ref. ro).

\section{EXPERIMENTAL}

\section{Preparation of stock emulsion}

An $8 \%$ hexadecane-water emulsion was prepared by mixing $8 \mathrm{ml}$ of hexadecane (Hexadecane Spectroquality Reagent, Matheson Coleman and Bell, Norwood, Ohio, U.S.A.) with I $\mathrm{ml}$ of $10 \%$ aqueous polysorbate 80 (obtained from Atlas Chemical Industries, Inc., Wilmington, Del., U.S.A.) solution and then diluting up to $100 \mathrm{ml}$ with distilled water. The mixture was then homogenized in a Waring blender for $75 \mathrm{sec}$, after which it was left to equilibrate at $30^{\circ}$ for $15^{-30}$ min while being in a Burrell Wrist-Action shaker (Burrell Corp., Pittsburgh, Pa., U.S.A.). The cumulative particle size distribution of this emulsion as determined with the Coulter Counter (see Fig. I, ref. ro) yielded a $95 \%$ mass balance (see Table I, ref. Io).

In all uptake and release experiments, dilutions corresponding to approx. 0.4 , $0.8, \mathrm{I} .2$ or $\mathrm{x} .6 \%$ oil were utilized. In the higher surfactant concentration emulsions, sufficient amounts of polysorbate 80 were added to make up the desired concentration after the homogenization step. The emulsion was then equilibrated as mentioned above and no significant changes in the particle size distribution were observed.

\section{Uptake experiments}

All radio-labelled solutes were obtained from New England Nuclear, Boston, Mass., U.S.A., or from Amersham/Searle Corp., Des Plaines, Ill., U.S.A. For a discussion of the purity of these compounds see Ph.D. thesis of A. B. BIKHAzI ${ }^{17}$.

Dilutions of the stock emulsion were made, and a predetermined amount of a solution containing the radio-labelled solute was added by means of a pipette. The mixture was then shaken gently in a Burrell Wrist-Action shaker at $30^{\circ} \cdot 5$-ml samples were pipetted out at different times and the aqueous phases immediately centrifuged (Lourdes Instrument Corp., Brooklyn, N. Y., U.S.A.) at 2 I $600 \times g$ for I.5 min. Utilizing extreme caution so as not to disturb the lower aqueous phase, the upper emulsion layers were sucked out using a water aspirator vacuum. Then exactly I-ml aliquots of the aqueous layers were pipetted out into scintillation vials. To each of the latter, ro $\mathrm{ml}$ of liquid scintillation cocktail were added, and the radioactivity determined with the Beckman liquid scintillation system (Beckman Instruments, Inc., Fullerton, Calif., U.S.A.) (Model 200).

\section{Release experiments}

For these experiments stock emulsions were prepared in a manner similar to those used in the uptake experiments. However, a specified amount of the radiolabelled solute was dissolved in the hexadecane prior to emulsification. Aliquots of this stock emulsion were then added at zero time to predetermined volumes of the corresponding polysorbate 80 solutions. Sampling and the analysis of the aqueous phases were conducted as in the uptake experiments. 


\section{Partition coefficient determination}

The hexadecane--polysorbate 80 partition coefficients for the solutes studied were calculated from 48 to $72 \mathrm{~h}$ data obtained from all uptake and release experiments. In addition, partition coefficients were determined from non-emulsified systems containing the same amount of hexadecane and aqueous polysorbate 80 . In general the same partition coefficient values were obtained with the emulsified and non-emulsified oil. This supports the assumption that solute accumulation at the oil/water interface is negligible and therefore permits the use of the simple model (Fig. I) and eliminating the need to consider more complex models ${ }^{6}$. Table I gives the partition coefficients of some of the solutes studied"

\section{TABLE I}

THE CALCULATED HEXADECANE-POLYSORBATE 80 PARTITION COEFFICIENTS OF THE SOLUTES STUDIED IN THE DIFFERENT POLYSORBATE 8O SYSTEMS AT $30^{\circ}$

Values calculated to within $\pm 10 \%$.

\begin{tabular}{lllll}
\hline Solute & $\begin{array}{l}\text { o.1\% } \\
\text { polysorbate } 80\end{array}$ & $\begin{array}{l}0.3 \% \\
\text { polysorbate } 80\end{array}$ & $\begin{array}{l}0.5 \% \\
\text { polysorbate 8o }\end{array}$ & $\begin{array}{l}\text { I.0\% } \\
\text { polysorbate 8o }\end{array}$ \\
\hline Cholesterol & 200 & 100 & - & 45 \\
$\beta$-Sitosterol & 200 & - & 72 & 44 \\
Desmosterol & 200 & - & 70 & 47 \\
$20 \alpha$-Hydroxycholesterol & 180 & - & - & - \\
Vitamin $D_{3}$ & 114 & - & -5 & - \\
\hline
\end{tabular}

\section{RESULTS AND DISCUSSION}

\section{The deiermination of the permeability coefficients}

The results of the experiments for the uptake and release of the various solutes are presented in Figs. 2-6. The average experimental partition coefficients calculated

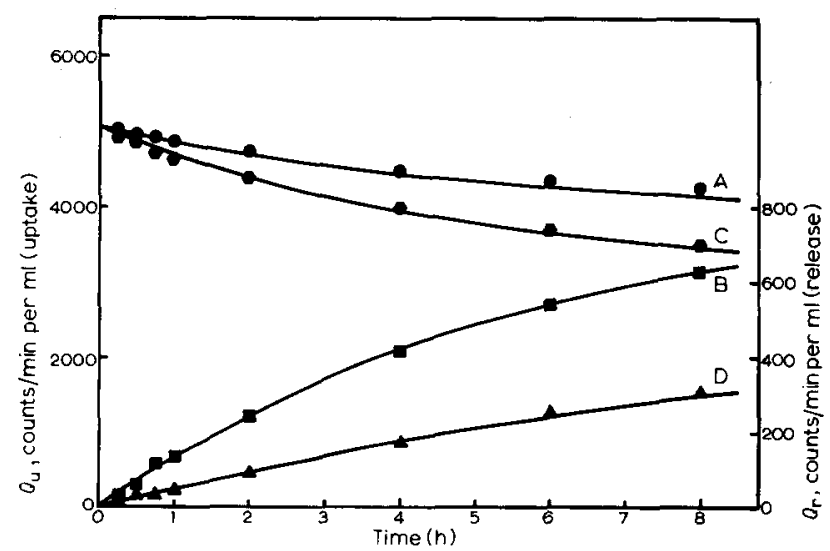

Fig. 2. Comparison of experimental data with theory for the uptake and release of cholesterol at $0.3 \%$ and $\mathbf{I} \%$ polysorbate 80 concentrations by Emulsion System I. $Q_{u}$ and $Q_{r}$ versus time in $\mathrm{h}$. A, experimental uptake points from $0.8 \%$ oil at $\mathrm{I} \%$ polysorbate $80, c_{b}=4500$ counts $/ \mathrm{min}$ per $\mathrm{ml}$; $B$, experimental release points from $0.8 \%$ oil at $\mathrm{I} \%$ polysorbate $80, c_{b}^{\prime}=200$ counts $/ \mathrm{min}$ per ml, $c_{o i}={ }_{1} 4000$ counts $/ \mathrm{min}$ per $\mathrm{ml}$. $P$ values for both system is $1.0 \cdot 10^{-7} \mathrm{~cm} \cdot \mathrm{sec}^{-1} ; \mathrm{C}$, experimental uptake points from $1.2 \%$ oil at $0.3 \%$ polysorbate $80, c_{b}=4500$ counts $/ \mathrm{min}$ per $\mathrm{ml}$; D, experimental release points from $0.8 \%$ oil at $0.3 \%$ polysorbate $80, c_{b}^{\prime}=200$ counts $/ \mathrm{min}$ per $\mathrm{ml}, c_{o i}=$ I 4 o ooo counts/min per ml. $P$ value for both systems is $1.2 \cdot 10^{-7} \mathrm{~cm} \cdot \mathrm{sec}^{-1}$. 
from the data for both uptake and release are presented in Table I. These data were used in the best fit procedure described above to determine the permeability coefficients, $P$, which are presented in Table II.

The time dependence agreements between the experimental data and the theoretical predictions given by the curves in Figs. 2-6, were found to be generally good and therefore support the quantitative reliability of the $P$ values thus obtained (see Ph.D. thesis of A. B. BIKHAZI ${ }^{17}$ for additional examples at other oil/water ratios and

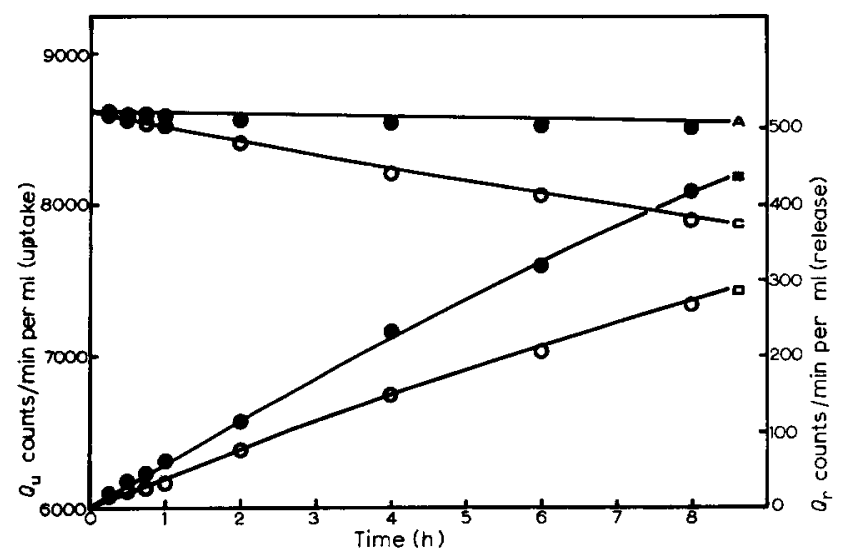

Fig. 3. Comparison of experimental data with theory for the uptake and release of $\beta$-sitosterol at $0.5 \%$ and $\mathrm{I} \%$ polysorbate 80 concentrations by $0.8 \%$ oil from Emulsion System I. $Q_{u}$ and $Q_{r}$ versus time in $\mathrm{h}$. A, experimental uptake points at $\mathrm{I} \%$ polysorbate $80, c_{b}=8600$ counts $/ \mathrm{min}$ per $\mathrm{ml} ; \mathrm{B}$, experimental release points at $\mathrm{I} \%$ polysorbate $80, c_{b}^{\prime}=278$ counts $/ \mathrm{min}$ per $\mathrm{ml}, c_{o i}=$ 280245 counts $/ \mathrm{min}$ per $\mathrm{ml}$; C, experimental uptake points at $0.5 \%$ polysorbate $80, c_{b}=8600$ counts $/ \mathrm{min}$ per $\mathrm{ml} ; \mathrm{D}$, experimental release points at $0.5 \%$ polysorbate $80, c_{b}^{\prime}=30_{4}$ counts $/ \mathrm{min}$ per $\mathrm{ml}, c_{o i}=28473^{8}$ counts $/ \mathrm{min}$ per $\mathrm{ml}$. $P$ value for all systems is $2 \cdot 5^{\cdot} \cdot \mathrm{IO}^{-8} \mathrm{~cm} \cdot \mathrm{sec}^{-1}$.

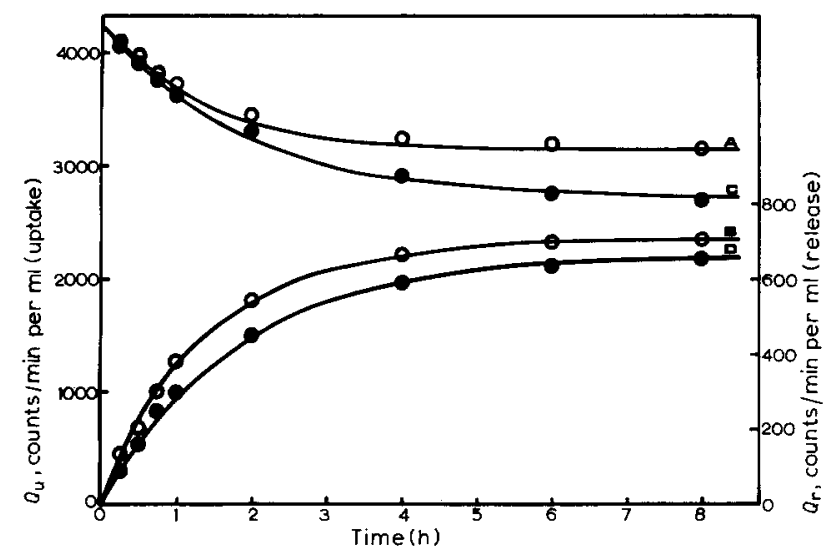

Fig. 4. Comparison of experimental data with theory for the uptake and release of desmosterol at $0.5 \%$ and $\mathrm{I} \%$ polysorbate 80 concentrations by $0.8 \%$ oil from Emulsion System I. $Q_{u}$ and $Q_{r}$ versus time in $h$. A, experimental uptake points at $1 \%$ polysorbate $80, c_{b}=4225$ counts $/ \mathrm{min}$ per $\mathrm{ml}$; B, experimental release points at $\mathrm{I} \%$ polysorbate $80, c_{b}^{\prime}=192 \mathrm{counts} / \mathrm{min}$ per $\mathrm{ml}, c_{o i}=$ I 39 I 38 counts $/ \mathrm{min}$ per $\mathrm{ml}$; $\mathrm{C}$, experimental uptake points at $0.5 \%$ polysorbate $80, c_{b}=4225$ counts $/ \mathrm{min}$ per $\mathrm{ml} ; \mathrm{D}$, experimental release points at $0.5 \%$ polysorbate $80, c_{b}^{\prime}=180$ counts $/ \mathrm{min}$ per $\mathrm{ml}, c_{o i}=150898$ counts $/ \mathrm{min}$ per $\mathrm{ml}$. $P$ value for all systems is $5 \cdot 10^{-7} \mathrm{~cm} \cdot \mathrm{sec}^{-1}$. 
surfactant concentrations.) Also in all cases, the $P$ values found were independent of the oil concentration of the emulsion.

Table II shows that the $P$ values for $20 \alpha$-hydroxycholesterol were generally much larger, by several order of magnitudes, than those for the other sterols. Among the other sterols, $20 \alpha$-hydroxycholesterol was the only one to exhibit a significant surfactant concentration dependence. The table also shows that the $P$ values for solutes other than the sterols were found to be much larger than, for example, cholesterol. These generally ranged from $\mathrm{IO}^{-4}$ to $\mathrm{IO}^{-5} \mathrm{~cm} \cdot \mathrm{sec}^{-1}$.

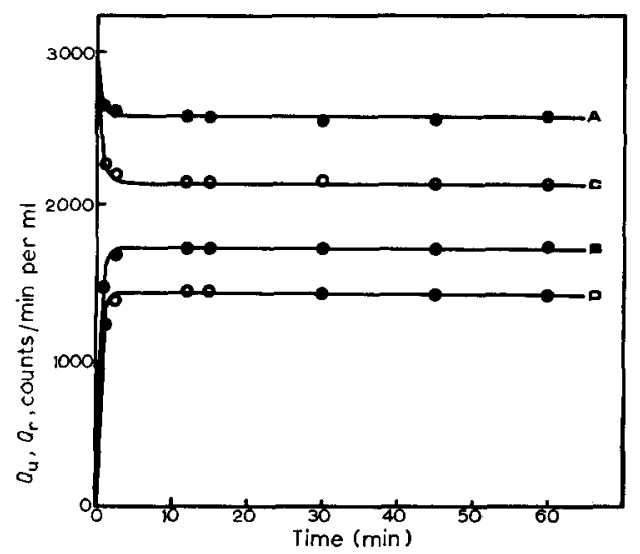

Fig. 5. Comparison of experimental data with theory for the uptake and release of $20 \alpha$-hydroxycholesterol at $0.5 \%$ and $\mathrm{I} \%$ polysorbate 80 by $0.8 \%$ dilution of Emulsion System $1 . Q_{u}$ and $Q_{\tau}$ versus time in min. A, experimental uptake points at $\mathrm{I} \%$ polysorbate $80, c_{b}=2950$ counts $/ \mathrm{min}$ per $\mathrm{ml} ; \mathrm{B}$, experimental release points at $\mathrm{I} \%$ polysorbate $80, c_{b}^{\prime}=300$ counts $/ \mathrm{min}$ per $\mathrm{mI}$, $c_{o i}=226240$ counts $/ \mathrm{min}$ per $\mathrm{ml} . P$ value is $5 \cdot 1 \mathrm{O}^{-5} \mathrm{~cm} \cdot \mathrm{sec}^{-1} ; \mathrm{C}$, experimental uptake points at $0.5 \%$ polysorbate $80, c_{b}=2950$ counts $/ \mathrm{min}$ per $\mathrm{ml} ; \mathrm{D}$, experimental release points at $0.5 \%$ polysorbate $80, c_{b}^{\prime}=308$ counts $/$ min per $\mathrm{ml}, c_{o i}=2378 \mathrm{II}$ counts $/ \mathrm{min}$ per $\mathrm{ml}$. $P$ value is $I_{1} \cdot \mathrm{I}^{-4}$ $\mathrm{cm} \cdot \mathrm{sec}^{-1}$.

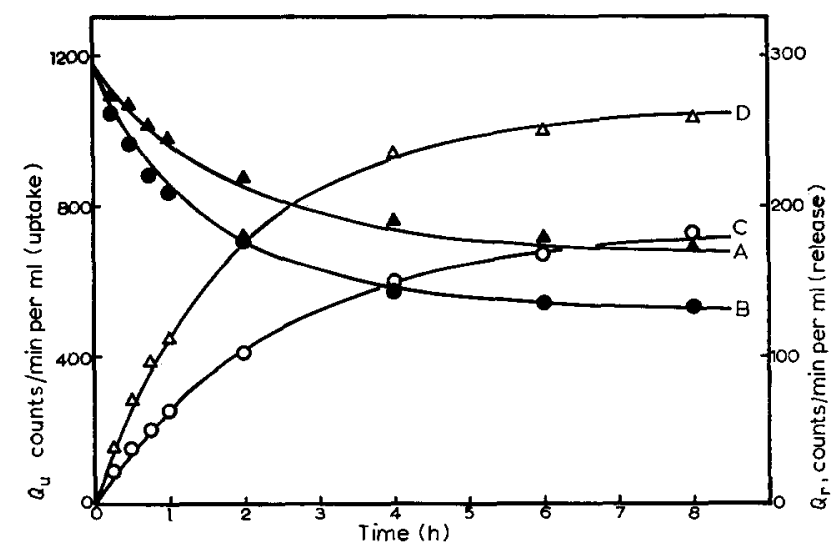

Fig. 6. Comparison of experimental data with theory for the uptake and release of vitamin $\mathrm{D}_{3}$ at $0 . \mathrm{I} \%$ polysorbate 80 by Emulsion System I. $Q_{u}$ and $Q_{r}$ versus time in $\mathrm{h}$. A, experimental uptake points by $0.8 \%$ oil, $c_{b}=1176$ counts $/ \mathrm{min}$ per $\mathrm{ml} ; \mathrm{B}$, experimental uptake points by $1.2 \%$ oil, $c_{b}=$ I I 76 counts $/ \mathrm{min}$ per $\mathrm{ml}$; C, experimental release points by $0.4 \%$ oil, $c_{b}^{\prime}=60$ counts $/$ min per $\mathrm{ml}, c_{o i}=66252$ counts $/ \mathrm{min}$ per $\mathrm{ml} ; \mathrm{D}$, experimental release points by $0.8 \%$ oil, $c_{b}^{\prime}=$ Ioo counts/ min per $\mathrm{ml}, c_{o i}=77625$ counts $/ \mathrm{min}$ per ml. $P$ value for both systems is $6 \cdot 10^{-7} \mathrm{~cm} \cdot \mathrm{sec}^{-1}$. 


\section{TABLE II}

EFFECTIVE PERMEABILITY COEFFICIENTS OF THE SOLUTES STUDIED IN THE INDICATED SYSTEMS

Units in $\mathrm{cm} \cdot \mathrm{sec}^{-1}$.

\begin{tabular}{|c|c|c|c|c|c|}
\hline Solute & $\begin{array}{l}\text { Hexadecane- } \\
o . r \% \\
\text { polysorbate } 80\end{array}$ & $\begin{array}{l}\text { Hexadecane- } \\
0.3 \% \\
\text { polysorbate } 80\end{array}$ & & $\begin{array}{l}\text { Hexadecane- } \\
0.5 \% \\
\text { polysorbate } 80\end{array}$ & $\begin{array}{l}\text { Hexadecane- } \\
I \% \\
\text { polysorbate } 80\end{array}$ \\
\hline Cholesterol & $1.7-2.2 \cdot 10^{-7}$ & $1.2 \cdot 10^{-7}$ & & 一 & $1.0 \cdot 10^{-7}$ \\
\hline$\beta$-Sitosterol & $2.5 \cdot 10^{-8}$ & - & & $2.5 \cdot 10^{-8}$ & $2.5 \cdot 10^{-8}$ \\
\hline Desmosterol & $5.0-6.0 \cdot 10^{-7}$ & - & & $5.0 \cdot 10^{-7}$ & $5.0 \cdot 10^{-7}$ \\
\hline $20 \alpha$-Hydroxycholesterol & $\sim 3.0 \cdot 10^{-4}$ & - & $\sim$ & $1.0 \cdot \mathrm{IO}^{-4}$ & $\sim 5.0 \cdot 10^{-5}$ \\
\hline Vitamin $\mathrm{D}_{3}$ & $6.0 \cdot 10^{-7}$ & 一 & & 一 & - \\
\hline Lithocholic acid & $\geq 1.0 \cdot 10^{-4}$ & - & & - & - \\
\hline Testosterone & $\geq 2.0 \cdot 10^{-5}$ & - & & - & - \\
\hline Progesterone & $\geq \mathrm{I} .0 \cdot \mathrm{IO}^{-4}$ & - & & 一 & - \\
\hline Octyl alcohol & $\geq 1.0 \cdot 10^{-4}$ & - & & - & - \\
\hline Cetyl alcohol & $\geq 1.0 \cdot 10^{-4}$ & - & & $\ldots$ & - \\
\hline Lauryl alcohol & $\geq 1.0 \cdot 10^{-4}$ & - & & - & - \\
\hline DDT & $\geq 2.0 \cdot 10^{-4}$ & - & & - & - \\
\hline
\end{tabular}

\section{Assessment of the method}

Fig. 7 is a normalized representation of the release data for the four sterols obtained in $0.1 \%$ polysorbate 80 . It illustrates the range of applicability of this technique. Essentially a roooo-fold range of permeability coefficient values is seen here. Actually, no lower limit for permeability coefficients determination exists if this system is chemically and physically stable.

The results of the experiments, the accompanying treatment of the data, and the consideration of the basic assumptions in Eqns. 7 and 8 show that the method is highly quantitative mechanistically. For example, the fits of the experimental data to the theory with single adjustable parameter, $P$, have been found to be extremely

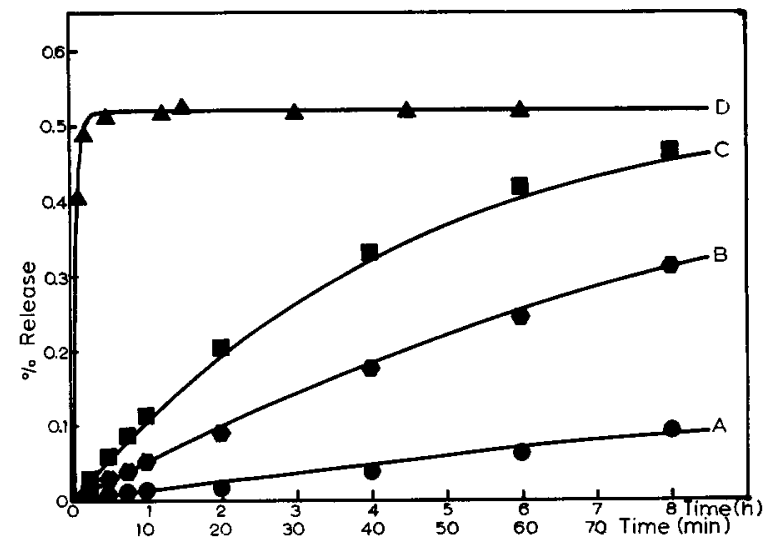

Fig. 7. Normalized representation to illustrate the range of applicability of the technique. Percent release versus time in $\mathrm{h}$ and $\min$ (for $20 \alpha$-hydroxycholesterol). A, $\beta$-sitosterol $P$ value is $2 \cdot 5^{\cdot 10^{-8}}$ $\mathrm{cm} \cdot \mathrm{sec}^{-1}, K$ value is $200 ; \mathrm{B}$, cholesterol $P$ value is $1.7 \cdot 10^{-7} \mathrm{~cm} \cdot \mathrm{sec}^{-1}, K$ value is $200 ; C$, desmoste-

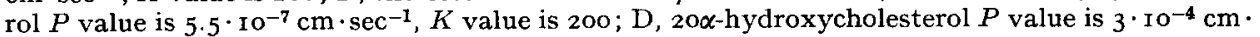
$\sec ^{-1}, K$ value is 180 
good in most instances (Figs. 2-6). Consequently, the meaning of the permeability coefficient is not physically ambiguous.

The method has been shown to be conveniently capable of determining interfacial barrier permeability coefficients of the order of $\mathrm{IO}^{-4} \mathrm{~cm} \cdot \mathrm{sec}^{-1}$ or smaller utilizing droplet particle sizes in the $1-6-\mu$ diameter size range. More rigid analytical techniques might improve the sensitivity to smaller interfacial barriers. However, it must be recognized that there is a theoretical upper limit value of $\sim D / a_{j}$ which in the present situations involving micelles is of the order of $\mathrm{IO}^{-3}-\mathrm{IO}^{-2} \mathrm{~cm} \cdot \mathrm{sec}^{-1}$ (ref. 5).

Possible physical meaning of the permeability coefficient and the proposed mechanism for transport of sterols across the polysorbate 8o-hexadecane interface

The model expressed by Eqns. 7 and 8 has not considered whether or not only free solute, i.e., non-micellar solute, is involved in the rate-determining step. It is possible then that either or both free solute and solute species interacting with polysorbate 80, e.g., micellized solute, in the aqueous phase may be crossing the interfacial barrier. In such cases, the $P$ values listed in Table II are effective permeability coefficients representing free solute and/or micelle solubilized transport phenomena.

If only free solute is involved in the transition state, i.e., the rate-determining transport step, one should expect $P$ to be a function of the ratio, $R$, of the free solute to the total solute in the aqueous phase so that

$P_{f}=P / R$

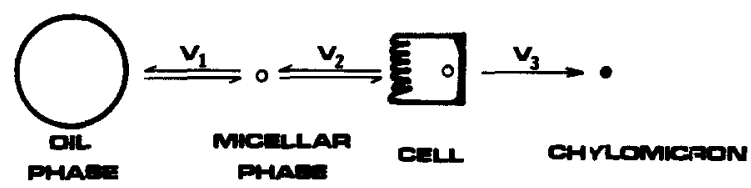

Mog-1 a

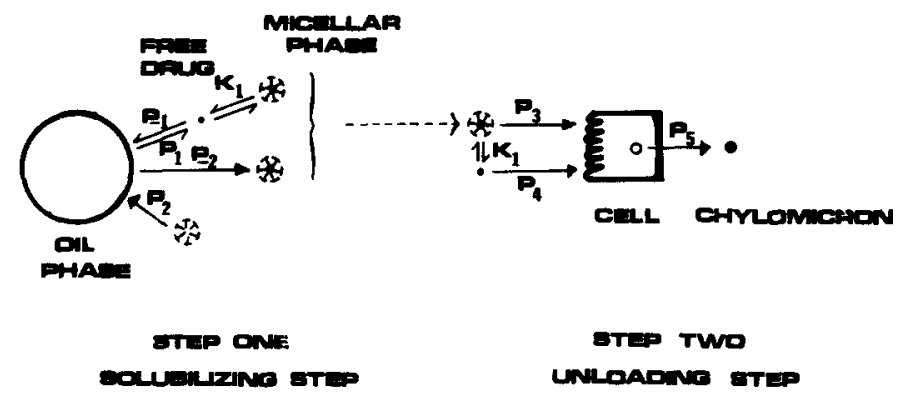

Morat $\mathrm{B}$

Fig. 8. Model A, Sylvèn-Borgström model for the absorption and digestion of fat ${ }^{21} . v_{1}$ is the rate of transfer from oil phase to micellar phase, $v_{2}$ is the rate of transfer from micellar phase to cell membrane, $v_{3}$ is the rate of transfer from the intestinal wall to the lymph. Model $\mathrm{B}$, modification to Sylvèn-Borgström model proposed as a result of the present work. The solubilizing rate is controlled by the rate constants $\mathrm{P}_{1}, \mathrm{P}_{-1}, P_{2}$, and $P_{-2} . K_{1}$ is an equilibrium constant. The unloading rate is controlled by $P_{3}$ and $P_{4}$. Release of solute and/or metabolite by the cell into lymph system is controlled by $P_{5}$. 
where $P_{f}$ is the interfacial permeability coefficient for the free solute and is constant for constant barrier conditions and independent of total solute in the aqueous phase. Thus, for example, suppose cholesterol were to be following this mechanism, then if $R=5 \cdot 1 \mathrm{O}^{-4}$, and $P \sim \mathrm{I} \cdot \mathrm{IO}^{-7} \mathrm{~cm} \cdot \mathrm{sec}^{-1}$, then $P_{f}=2 \cdot 1 \mathrm{O}^{-4} \mathrm{~cm} \cdot \mathrm{sec}^{-1}$ would be the true or intrinsic interfacial permeability coefficient of cholesterol across the interfacial barrier. As will be seen below, however, this interpretation seems to be the wrong one for at least cholesterol, $\beta$-sitosterol, and desmosterol in the polysorbate 80 -hexadecane system.

On the other hand, if the micellized solute were to be primarily involved in the transition state, then

$$
P_{m}=P(\mathrm{I}-R)
$$

would give the intrinsic permeability coefficient, $P_{m}$, for the interfacial transfer of the micelle solubilized solute.

Compelling arguments may now be presented that support a transition state involving the micelle rather than the free solute in the interfacial event. The dependence of $P$ upon the surfactant over a ro-fold surfactant concentration is negligible or small for cholesterol, $\beta$-sitosterol, and desmosterol. This strongly argues against the mechanism involving the free sterol only in the transition state. The activity or the concentration of the free sterol would be expected to be strongly dependent upon the reciprocal of the surfactant concentration. The possible direct effect of the surfactant concentration increase upon the barrier itself would, if anything, be expected to be in this same direction, i.e., a greater interfacial resistance at high surfactant concentrations. Therefore, it is difficult to conclude other than the micelle to be the primary deliverer of the solute in these cases.

While the uncertainties in the determined $P$ values in the $20 \alpha$-hydroxycholesterol experiments were greater than those for the other sterols, there appeared to be significant dependence of $P$ upon the surfactant concentration for this solute (see Table II), the relationship being essentially what is expected from Eqn. Io. Thus, it might be suggested that $20 \alpha$-hydroxycholesterol crosses the interfacial barrier alone.

\section{Further scrutiny of the interfacial event involving the micelle delivery}

The evidence considered thus far supports (a) the interfacial barrier controlling mechanism and (b) the micelle involvement in the delivery across the interface. It is now necessary to consider the relative $P$ values obtained for cholesterol, $\beta$-sitosterol and desmosterol.

It is noteworthy that the hexadecane--polysorbate 80 partition coefficients for the three solutes were found to be essentially the same (see Table I) even though significant functional group differences exist. The present invariant partition coefficient data for the three solutes can be rationalized on the following argument. If the micelle structures are similar for the three solute situations and if the relevant portions of the micelle solubilized sterol is in the hydrophobic interior of the micelle, then little dependence of $K$ upon solute structural changes should be expected as the partitioning would essentially be between one hydrocarbon environment to another.

With such a picture in mind, one might propose the following description of the transition state. The micelle must begin the approach to the interface as a result of an appropriate thermal fluctuation. Then somewhere prior to reaching the hexadecane 
"phase", the micelle unloading process must take place. The unloading must occur in an environment which is still aqueous or hydrophilic. If instead, the intact micelle carried the solute all the way into the hexadecane, it would be difficult to expect the large difference in the $P$ value between cholesterol and $\beta$-sitosterol unless the solutes had significantly different influences upon micelle structures - an unreasonable expectation. For the usual reasons, it is also more plausible to expect the relatively hydrophilic polysorbate 80 micelles not to penetrate all the way, but instead unload its cargo somewhere, part way, between the aqueous phase and the hexadecane phase.

The above mechanism can then account for all the experimental results found in this study. As will be seen below, this type of process might easily account for the observations in vivo regarding the gastrointestinal absorption of sterols and other fatsoluble compounds.

BORGSTRÖM ${ }^{18}$ has reported that cholesterol is taken up in the rat gut at a rate that is 5-Io times that for sitosterol even though the equilibrium distribution (partition) in vitro of the two sterols between the aqueous micellar phase and glycerides were essentially the same ${ }^{19}$. If any mechanism based upon a carrier micelle transport from the bulk intestinal phase to the surface of the mucosal side of the intestinal membrane were to be operative, such large differences between cholesterol and $\beta$-sitosterol would be unreasonable. Therefore, a rate-determining process occurring in, at, and/or "near" the mucosal side of the membrane should be a more acceptable one in this situation. The present studies not only support the interfacial barrier control model for cholesterol and $\beta$-sitosterol, but even the quantitative difference between these two sterols (viz. $P=2.5 \cdot 10^{-8} \mathrm{~cm} \cdot \mathrm{sec}^{-1}$ for $\beta$-sitosterol and $P=\mathrm{I} .7 \cdot 10^{-7} \mathrm{~cm} \cdot \mathrm{sec}^{-1}$ for cholesterol) are of the same order of magnitude as that found in the studies in vivo. Because the present physicochemical systems are quite different chemically from the situations in vivo, a generalization of our findings to more physiologically realistic model experimental systems would be desirable. The proposed mechanism, however, is certainly a very attractive one to explain the available biological data.

The proposed model (Model B) for the sterol absorption is given in Fig. 8. As discussed above, the new model stresses the importance of distinguishing the steps involved in the unloading process. Moreover, it is assumed in the model that the release of the solute from the micellar phase is essentially fast ${ }^{20}$. In the context of our research it is suggested that cholesterol and $\beta$-sitosterol follow Step $P_{3}$ rather than $P_{4}$ during unloading because of the relative insensitivity of the apparent permeability coefficient to the surfactant concentration. Furthermore, it is proposed that the differences in the transport rates between cholesterol and $\beta$-sitosterol occur as a result of the difference in the "transit" tendency of both sterols across a largely hydrophilic or aqueous region from an "activated" micelle.

\section{ACKNOWLEDGMENTS}

This investigation was supported by National Institute of General Medical Sciences Grant GM-I3368 and by National Heart Institute Grant HE-o769o. 


\section{REFERENCES}

i P. Mueller, D. O. Rudin, H. T. Tien and W. C. Wescott, in J. F. Danielli, A. C. RiddiFord and M. D. Rosenberg, Recent Progress in Surface Science, Vol. I, Academic Press, New York and London, I964, p. 379.

2 R. C. Bean, W. C. Shepherd and H. Chan, J. Gen. Physiol., 52 (1968) 495.

3 R. E. Wood, F. P. Wirth and H. E. Morgan, Biochim. Biophys. Acta, I63 (1968) I7r.

4 P. G. Lefevre, C. Y. Jung and J. E. Chaney, Arch. Biochem. Biophys., i 26 (I968) 677.

5 A. H. Goldberg, W. I. Higuchi, N. F. H. Ho and G. Zografi, J. Pharm. Sci., 58 (I967) I 432.

6 A. H. Ghanem, W. I. Higuchi and A. P. Simonelli, J. Pharm. Sci., 58 (1969) 165.

7 A. H. Ghanem, W. I. Higuchi and A. P. Simonelli, J. Pharm. Sci., 59 (i97o) 232.

8 A. H. Ghanem, W. I. Higuchi and A. P. Simonelli, J. Pharm. Sci., 59 (1970) 659.

9 L. B. Holder and S. L. Hayes, Mol. Pharmacol., i (1965) 266.

io A. B. Bikhazi and W. I. Higuchi, $J$. Pharm. Sci., 59 (1970) 744.

i W. I. Higuchi, A. H. Ghanem and A. B. Bikhazi, Federation Proc., 29 (I970) I327.

I2 A. Suzuki, W. I. Higuchi and N. F. H. Ho, J. Pharm. Sci., 59 (I970) 644.

I3 A. Suzuki, W. I. Higuchi and N. F. H. Ho, J. Pharm. Sci., 59 (I970) 651 .

I4 H. L. Rosano, P. Duby and J. Schulman, J. Phys. Chem., 65 (I961) I 704.

I 5 W. I. Higuchi, J. Pharm. Sci., 53 (1964) 405.

I6 A. H. Goldberg and W. I. Higuchi, $J$. Pharm. Sci., 58 (I969) I 34I.

I 7 A. B. BıкнAzI, Interfacial Barrier Limited Transport of Some Organic Solutes Across the Hexadecane-Polysorbate 80 Interface, Ph.D. thesis, University of Michigan, Ann Arbor, Mich., 1970.

I 8 B. Borgström, J. Lipid Res., 9 (I968) 473.

I9 B. Borgström, J. Lipid Res., 8 (1967) 598.

20 H. Matsumoto, Chem. Pharm. Bull., I 4 (1966) 398.

2 I C. Sylven and B. Borgström, J. Lipid Res., 9 (I968) 596.

Biochim. Biophys. Acta, 233 (1971) 676-687 